\title{
Determination of the Intermolecular Entanglement Coupling Spacings in Polyisoprene by Viscosity Measurements
}

\author{
Lewis J. Fetters*
}

(August 14, 1964)

\begin{abstract}
The entanglement molecular weight $\left(M_{e}\right)$ for polyisoprene has been estimated from the dependence of solution viscosity on molecular weight. Polymer concentrations of 1.82, 3.64 , and $14.56 \mathrm{~g} / 100 \mathrm{~cm}^{3}$ were used. Certain theoretical relationships between viscosity and molecular weight have been confirmed, and the prediction concerning the dependence of the entanglement molecular weight on polymer concentration has been substantiated. Furthermore, no variation in $M_{e}$ was detected in the range of 25 to $75^{\circ} \mathrm{C}$.
\end{abstract}

\section{Introduction}

In the prevailing conceptual scheme $[1]^{1}$ of entanglement coupling, the parameter, $M_{e}$, is defined as the average molecular weight of a chain segment between intermolecular junction points $[1,2]$. The presence of these chain entanglements markedly influences the viscoelastic properties of undiluted polymers and their concentrated solutions. Hence, these entanglements behave as mobile transient cross-links $[3,4]$.

Some commonly employed methods $[1,2,5]$ for characterizing entanglement spacings involve the analysis of the value of the storage modulus $G^{\prime}(\omega)$, the relaxation modulus $G(t)$, the storage compliance $J^{\prime}(\omega)$, or the creep compliance $J(t)$ in the vicinity of the time or frequency scale where the slope of the complex modulus or compliance versus time or frequency curve is very small and possesses an inflection point. Hence, by utilizing this value as a pseudo-equilibrium modulus, $G_{e}$, or compliance, $J_{e}$, it is possible to estimate the average molecular weight between the entanglement loci from rubber elasticity theory $[6,7]$. In addition, the position and value of the maximum in the loss compliance, $J^{\prime \prime}(\omega)$, have also been used $[2,8,9]$ to determine the magnitude of $M_{e}$. However, as it has been pointed out elsewhere $[1,10]$, since the adequacy of the theories upon which these dynamic methods are based is not high, the quantitative results concerning entanglements obtained by their use may be suspect. In addition, further difficulty is sometimes encountered in selecting a suitable value of $G_{e}$ or $J_{e}$.

The measurement of viscosity should provide an accurate and precise tool for investigating chain entanglements, since the effect of these intermolecular couplings on viscosity is very large. Em-

\footnotetext{
* National Academy of Sciences-National Research Council Postdoctoral Resident Research Associate.

1 Figures in brackets indicate the literature references at the end of this paper.
}

pirically [11], it is recognized that in the region in which the molecular weights of an undiluted polymer system are above some critical value, $M_{c}$, characteristic of the polymer's chemical structure, the following relation is found to hold:

$$
\log \eta=\log K+3.4 \log M
$$

where $M$ is the molecular weight of the polymer and the constant $K$ depends upon temperature and the nature of the polymer. The above relation is also valid for concentrated solutions provided the following relation is obeyed $[1,11,12]$.

$$
v_{2} M \geqslant M_{c}
$$

where $v_{2}$ denotes the volume fraction of polymer. For polymers possessing molecular weights below the minimum chain length required for incipient entanglement network formation, the observed viscosity is approximately proportional to the molecular weight.

These empirical facts can be interpreted in terms of the theoretical derivations of Eyring [13] and Bueche [14]. In the region where the polymer molecular weight is above its critical value, the long chain interactions are usually thought of as being communicated through the valence bonds and entanglement points. Hence, the polymer system is considered to consist of a loosely bound infinite network of intermeshed chains which tend to drag each other along as they slide over one another in flow. A precise picture of these entanglements does not currently exist.

The purpose of this paper is to present a reasonably accurate estimate of the magnitude of the entanglement spacings in polyisoprene. In addition, the effects of moderate variations in temperature and concentration on the spacing of the coupling points are reported. Conflicting conclusions concerning: these two variables have appeared in the literature in conjunction with various polymeric systems. 


\section{Experimental Procedures}

For the determination of $M_{e}$ from the dependence of viscosity on molecular weight, a number of polymer samples of known molecular weight must be used. Recent advances [15-25] in homogeneous anionic polymerization now permit the synthesis of linear, nearly monodisperse polyisoprene, which is structurally a close counterpart of Hevea rubber. The samples used in this work were prepared by the $n$-butyllithium-initiated polymerization of isoprene in $n$-hexane. Care was taken to maintain the reaction conditions [20, 24-26] which facilitate the formation of linear, relatively monodisperse polymer with a cis-1,4 content of 90-95 percent. Polyisoprene formed by the heterogeneous Ziegler-Natta catalysts, e.g., triisobutyl aluminum and $\mathrm{TiCl}_{4}$, is unsuitable [27-29], since the resultant polymer has a broad molecular weight distribution and contains some branched polymer as well as microgel, which is difficult to separate by fractionation alone.

Characterization of four of the samples indicated, as expected, that linear polymer, with a narrow distribution $\left(\bar{M}_{w} / \bar{M}_{n}=1.11-1.03\right)$ of molecular weights, was indeed formed. The samples were stored in the terminated state, under vacuum, at -20 ${ }^{\circ} \mathrm{C}$ until just prior to use. This kind of storage does not impair the structural integrity of the polymer [30]. The molecular weights reported here are from intrinsic viscosity measurements in toluene by use of the following relations:

$$
\begin{aligned}
{[\eta]_{30}{ }^{\circ} \mathrm{C} } & =2.00 \times 10^{-4} \bar{M}_{w}{ }^{0.728}[29] \\
\left.{ }_{\eta}\right]_{25}{ }^{\circ} \mathrm{C} & =1.08 \times 10^{-4} \bar{M}_{n}{ }^{0.82}[31]
\end{aligned}
$$

Equation (1) was used for samples with molecular weights greater than $1.5 \times 10^{5}$ while eq $(2)$ was applied to the samples with molecular weights in the range of $2.5 \times 10^{4}$ to $1.5 \times 10^{5}$. The samples prepared had molecular weights which ranged from $2.5 \times 10^{4}$ to $1.3 \times 10^{6}$.

All of the concentrated solution viscosity measurements were taken at very low shear rates. Corrections for rate of shear proved to be very small under the experimental conditions employed. Henceforth the results given here are those one would obtain at zero rate of shear.

Solution of the polymers was carried out in decane. The viscosities were measured in capillary viscometers, which had been calibrated by the use of standard viscosity oils supplied by the National Bureau of Standards. Viscosities of the polyisoprene-decane solutions were measured at temperatures of $25{ }^{\circ} \mathrm{C}$ and $75{ }^{\circ} \mathrm{C}$ and at concentrations of $1.82 \mathrm{~g}, 3.64 \mathrm{~g}$, and $14.56 \mathrm{~g} / 100 \mathrm{~cm}^{3}$ of solution. The density of the synthetic polyisoprene was taken as $0.91 \mathrm{~g} / \mathrm{cm}^{3}$. The reported viscosities are expressed in poises. Molecular disintegration under the employed experimental conditions was undetectable.

\section{Results and Discussion}

The viscosity-molecular weight relationships of the various solutions are presented in figures 1,2 , and 3 . For a particular polymer the point of intersection of the straight lines, the "break" point, defines a characteristic polymer molecular weight $M_{b}$, i.e., the molecular weight at the "break" point. From this value, $M_{c}$ can be calculated from the following relation: $[1,11,12]$

$$
v_{2} M_{b} \simeq M_{c}
$$

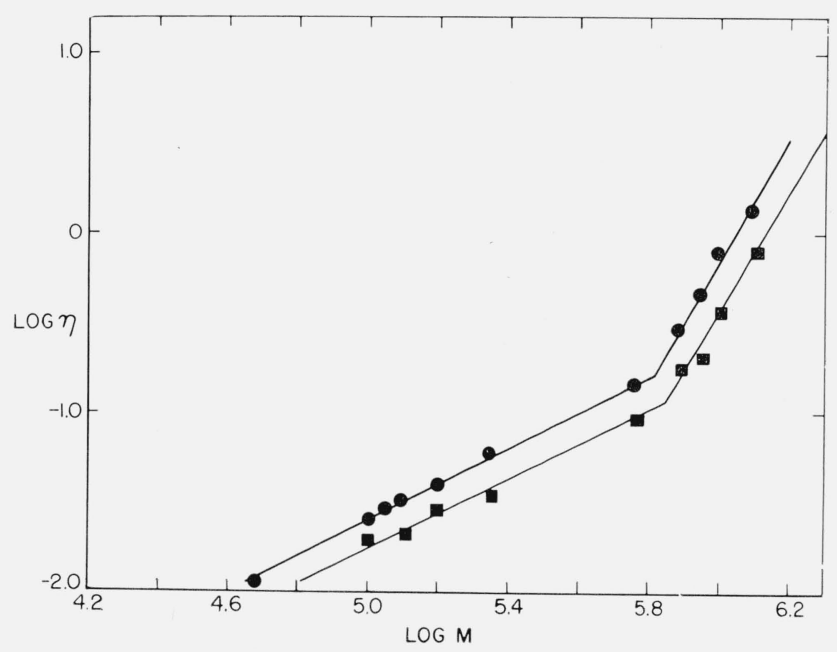

Figure 1. Zero shear viscosities of polyisoprene in decane at a concentration of 2.5 weight percent.

‥ $25^{\circ} \mathrm{C}$

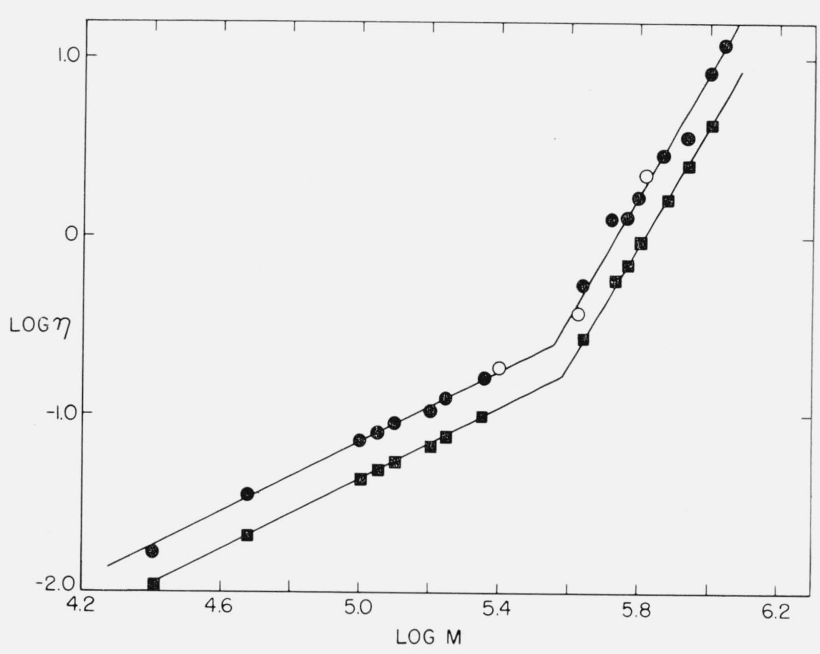

Figure 2. Zero shear viscosities of polyisoprene in decane at a concentration of 4.9 weight percent.

, $25^{\circ} \mathrm{C}$

0 , cis- 1,4 content 70 to 85 percent 


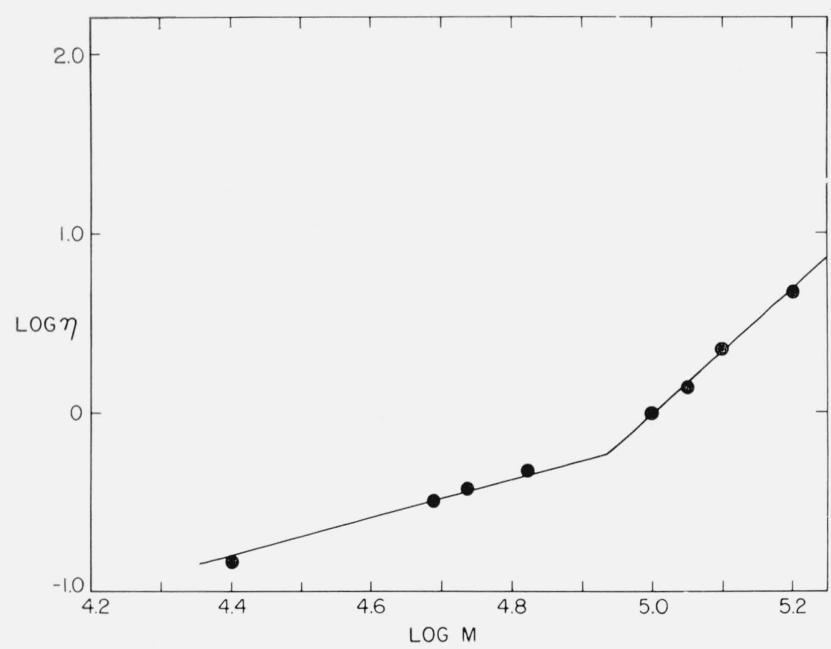

Figure 3. Zero shear viscosities for polyisoprene in decane at a concentration of 19.2 weight percent.

- $25^{\circ} \mathrm{C}$

Table 1 lists the pertinent data collected from

TABLE 1

\begin{tabular}{c|c|c|c|c|c}
\hline \hline $\begin{array}{c}\text { Polymer con- } \\
\text { centration (wt } \\
\text { percent) }\end{array}$ & $T$ & $M_{b} \quad 10^{-4}$ & $M_{c} \quad 10^{-3}$ & $a^{*}$ & $b^{*}$ \\
\cline { 1 - 2 } & & & & & \\
\hline & ${ }^{\circ} C$ & & & & \\
2.5 & 25 & 66.0 & 13.2 & 3.40 & 1.00 \\
4.9 & 75 & 71.5 & 14.0 & 3.38 & 0.98 \\
& 25 & 35.5 & 14.2 & 3.38 & .99 \\
19.2 & 75 & 37.6 & 14.2 & 3.40 & .98 \\
& 25 & 8.6 & 13.8 & 3.41 & 1.05 \\
\hline
\end{tabular}

${ }^{*} a$ and $b$ denote the slopes of the intersecting straight lines above and below the transition point, respectively.

figures 1 to 3 . The polymer concentrations reported correspond to volume percent values of 2,4 , and 16 at $25^{\circ} \mathrm{C}$. Since each sample served for measurements at the two temperatures, it was necessary to correct for the density change at the higher temperature in order to accurately calculate $M_{c}$ at $75{ }^{\circ} \mathrm{C}$.

These results clearly indicate the existence of the transition point to at least two volume percent concentration and the inverse first power dependence of the molecular weight for transition $\left(M_{b}\right)$ on concentration. This latter point is at variance with the interpretation given to data obtained from studies [32-34] of the dynamic behavior of a series of methacrylates. It was ascertained that $M_{c} \sim c^{-2.3}$ for this polymer series. A somewhat similar result has been reached from studies [35] carried out on solutions of polystyrene. From low-shear viscosity polymer-concentration plots, it was ascertained that $M_{c} \sim c^{-2}$.

The constancy of the molecular weight-concentration product found for the polyisoprene solutions is in complete accord with the results obtained from investigations [36-42] of the rheological behavior of polystyrene and polyisobutylene in bulk and concentrated solutions. A similar conclusion is reached from the combined results of Bueche $[10,12]$ and Bletso [43] for solutions of poly(methyl methacrylate).

Data acquired by the use of dynamic methods for a series of methacrylate polymers indicate that $M_{c}$ is temperature dependent $[2,32-34,44]$, i.e., the entanglements tend to dissociate with increasing temperature. In conjunction with his point, it should also be mentioned that a slight dependence of $M_{c}$ on temperature was apparently found [45, 46] for polyethylene when the relationship between viscosity and molecular weight was determined at 110 and $160{ }^{\circ} \mathrm{C}$.

However, the insensitivity of $M_{c}$ to temperature variations has been demonstrated by bulk and solution viscosity measurements of polystyrene and polyisobutylene $[11,37-39]$. Similar results were obtained from studies on the concentrated solutions of poly (methyl methacrylate) [10] and the undiluted polybutadiene [47] system.

These findings tend to corroborate the results reported in table 1 . Clearly the increase in temperature from $25^{\circ} \mathrm{C}$ to $75^{\circ} \mathrm{C}$ has not seriously altered $M_{c}$. One can say that if temperature variations in $M_{c}$ do occur, they are not very large.

In conclusion, it can be seen that the values of $a$ and $b$ are in close accord with the values of 3.5 and 1.0 predicted by Bueche [14] and Hayashi [48] as well as those of 3.33 and 1.33 as predicted by Eyring [13]. It might be added that these results are in semiquantitative agreement with the theoretical derivations of Chikahisa [49]. Tentative conclusions pertaining to the close agreement of the theoretical and empirical values of $a$ are reported elsewhere [50].

The value of $M_{e}$ has been regarded as being equivalent to $M_{c} / 2$, based on considering [8] the entanglement points to be located near the center of the polymer chains. This factor of two has also been justified on the basis of the hypothesis [12] that both accelerating and retarding elements simultaneously exist within the flowing system.

It has recently been proposed [5] that the introduction of this factor of two is perhaps unwarranted. In analogy with gelation theory [51], Markovitz, Fox, and Ferry [5] contend that, at the point of network formation, since there is one cross-linked unit on each of the joined chains in the cross-linkage, there exists, on the average, one cross-linked unit per primary polymer chain. From this point of view the molecular weight at the transition point $\left(\boldsymbol{M}_{c}\right)$ is equal to the average molecular weight $\left(M_{e}\right)$ between the intermolecular junction points. Eyring [13] has also identified $M_{c}$ as equivalent to $M_{e}$. However, pending future developments, final conclusions as to the exact relationship between $M_{c}$ and $M_{e}$ must currently be left in abeyance.

In lieu of $M_{\epsilon}$, the symbol $Z$ has been applied to denote the magnitude of the spacings between nearest coupling points. The term $Z$ however has multiple significance - a frequent occurrence in polymer science. It may denote either the degree of polymerization or the number of chain atoms between the coupling loci. In an attempt to obviate this multiplicity of meaning, it has been suggested [5 that the degree of entanglement spacing be expressed 
in terms of the average number of chain bonds between nearest entanglement points. For this purpose, it has been proposed that the symbol $\Lambda$ be adopted to denote this value. This nomenclature is used for the presentation of the data in table 2 where the various values of $\Lambda$, as determined from elastic measurements, are presented. For comparison, two recently reported values of $\Lambda$ for polybutadiene are also included.

TABLE 2. Estimates of $\Lambda$ for Hevea rubber and synthetic polydienes*

\begin{tabular}{|c|c|c|c|c|c|c|}
\hline \multirow{2}{*}{ Polymer } & \multicolumn{2}{|c|}{ Max. in $J^{\prime \prime}$} & \multirow{2}{*}{$\begin{array}{l}\text { Inflec- } \\
\text { tion in } \\
G^{\prime}(\omega)\end{array}$} & \multirow{2}{*}{$\begin{array}{l}\text { Inflec- } \\
\text { tion in } \\
J(t)\end{array}$} & \multirow{2}{*}{$\begin{array}{l}\text { Depend- } \\
\text { ence of } \\
\eta \text { on } M\end{array}$} & \multirow{2}{*}{ Reference } \\
\hline & $J^{\prime \prime}{ }_{m}$ & $\omega_{m}$ & & & & \\
\hline $\begin{array}{l}\text { Hevea rubber } \\
\\
\text { Synthetic } \\
\text { polyisoprene } \\
\text { polybutadiene* }\end{array}$ & 272 & 400 & $\begin{array}{l}120 ; 400 \\
296\end{array}$ & 504 & $\begin{array}{l}824 \\
414\end{array}$ & $\begin{array}{r}52 \\
53 \\
54 \\
\text { This work } \\
47\end{array}$ \\
\hline
\end{tabular}

* Portions of the data presented herein have cone from a recent compilation presented elsewhere [5].

${ }^{* *}$ Microstructure: 10 percent vinyl; 40 percent cis-1, 4; and 50 percent trans-1, 4

In presenting the value of $\Lambda$ determined from the dependence of $\eta$ on $M$, the value of $M_{c}$ has been taken as equal to $M_{e}$. Thus, $\Lambda$ is equal to $4 M_{c} / M_{0}$; where $M_{0}$ denotes the monomer molecular weight. If, however, the introduction of the factor of two should prove to be valid, the values of $\Lambda$, as presented herein, determined from the viscosity technique and from the position and value of the maximum of the loss compliance, $J^{\prime \prime}(\omega)$, should be divided by two. The factor of two can be introduced into the data obtained from the loss compliance since these values involve assumptions similar to those used in the treatment of the viscosity-molecular weight relation. Since there exists no uncertainty involving a factor of two in the calculations of $\Lambda$ involving the pseudoequilibrium modulus or compliance, these estimates of the entanglement spacings would remain unchanged.

It would appear that the value of $\Lambda$ reported herein should be applicable to Hevea rubber. However, there may exist some subtle structural differences between the two polyisoprenes which might render the foregoing conclusion invalid. Qualitatively, this aspect was briefly investigated. Several samples of polyisoprene were prepared under conditions which yield polymer with a cis-1,4 content of 70 to 85 percent. Their flow behavior, figure 2, was similar to polyisoprenes with the higher cis-1,4 content. This apparent insensititivy of the flow properties to small structural changes may indicate that the minute differences in microstructure between Hevea rubber and synthetic polyisoprene may not cause any great differences in $\Lambda$ for the two polydienes.

The author wishes to express his thanks to Lee A. Dunlap for his experimental assistance in the intrinsic viscosity determinations. Several conversations with F. Bueche are gratefully recalled.

\section{References}

[1] F. Bueche, Physical Properties of Polymers (John Wiley and Sons, Inc., New York, N.Y., 1962).

[2] J. D. Ferry, Viscoelastic Properties of Polymers, (John Wiley and Sons, Inc., New York, N.Y., 1961).

[3] R. Buchdahl, J. Colloid Sci. 3, 87 (1948).

[4] L. E. Nielson and R. Buchdahl, J. Chem. Phys. 17, 839 (1949); J. Colloid Sci. 5, 282 (1950).

[5] H. Markovitz, T. G Fox, and J. D. Ferry, J. Phys. Chem. 66, 1567 (1962); Polymer Preprints 3, No. 1, 12 (1962).

[6] H. Mark and A. V. Tobolsky, Physical Chemistry of High Polymeric Systems, (Interscience Publishers, New York, N.Y., 1950).

[7] J. D. Ferry, R. F. Landel, and M. L. Williams, J. Appl. Phys. 26, 359 (1955)

[8] R. S. Marvin, Chapter in J. T. Bergen, Ed., Viscoelasticity: Phenomenological Aspects, (Academic Press, Inc., New York, N.Y., 1960).

[9] H. Oser and R. S. Marvin, J. Res. NBS 67B (Math. and Math. Phys.) No. 2, 87 (1963).

[10] F. Bueche, C. J. Coven, and B. J. Kinzig, J. Chem. Phys, 39, 128 (1963).

[11] T. G Fox, S. Gratch, and S. Loshaek, Chapter in F. Eirich, Ed., Rheology, Theory and Applications, Vol. I, (Academic Press, Inc., New York, N.Y., 1956).

[12] F. Bueche, J. Appl. Phys. 26, 738 (1955).

[13] H. Eyring, T. Ree, and N. Hirai, Proc. Natl. Acad. Sci. 44, 1213 (1958).

[14] F. Bueche, J. Chem. Phys. 20, 1959 (1952); 25, 599 (1956).

[15] H. Morita and A. V. Tobolsky, J. Am. Chem. Soc. 99 , $5853(1957)$.

[16] H. Hsieh, D. J. Kelly, and A. V. Tobolsky, J. Polymer Sci. 26, 240 (1957).

[17] F. W. Stavely et al., Ind. Eng. Chem. 48, 778 (1956)

[18] A. V. Tobolsky and C. E. Rogers, J. Polymer Sci. 40, 73 (1959).

[19] S. E. Bresler, A. A. Korotkov, M. I. Mosevitsky, and I. Ya. Poddubnyi, Zhur. Tekh. Fiz. 28, 114 (1958).

[20] M. Morton, E. E. Bostick, and R. G. Clarke, J. Polymer Sci. 1A, 475 (1963).

[21] M. Morton, E. E. Bostick, R. A. Livigni, and L. J. Fetters, J. Polymer Sci. 1A, 1735 (1963).

[22] M. Morton, E. E. Bostick, and L. J. Fetters, J. Polymer Sci., Part C, No. 1, 311 (1963).

[23] N. Cálderon and K. W. Seott, Polymer Preprints 4, No. 2, 154 (1963).

[24] M. Morton, N. Calderon, L. J. Fetters, and J. F. Meier, Polymer Preprints 2, No. 2, 310 (1961).

[25] R. E. Stearns and L. A. Forman, J. Polymer Sci. 41, 381 (1959).

[26] E. Bauer and M. Magat, J. Chim. Phys. 47, 841 (1950).

[27] L. I. Zakharkin, Doklady Akad. Nauk, SSSR 131, 1069 (1960).

[28] W. M. Saltman, W. E. Gibbs, and J. Lal, J. Am. Chem. Soc. 80, 5615 (1958).

[29] W. H. Beattie and C. Booth, J. Appl. Polymer Sci., , 507 (1963).

[30] J. F. Meier, Ph.D. Thesis, University of Akron, Akron, Ohio (1963).

[31] M. Morton and H. Brantley, unpublished results.

[32] D. M. Stern, J. W. Berge, S. F. Kurath, C. Sakoonkim, and J. D. Ferry, J. Colloid Sci. 17, 409 (1962).

[33] T. P. Yin and J. D. Ferry, J. Colloid Sci. 16, 166 (1961).

[34] T. E. Newlin, S. E. Lovell, P. R. Saunders, and J. D. Ferry, J. Colloid Sci. 1\%, 10 (1962).

[35] S. Onogi, T. Kobayashi, Y. Kojima, and T. Taniguchi, Trans. Soc. Rheology 6, 390 (1962); J. Appl. Polymer Sci. $\boldsymbol{y}, 847$ (1963).

[36] T. Kotaka, M. Kurata, and M. Tamura, Rheology Acta. ק, 179 (1962).

[37] F. Bueche and F. Kelly, J. Polymer Sci. 45, 267 (1960); ibid. 50, 549 (1961).

[38] T. G Fox and V. Allen, Conference on High Temperature Polymer and Fluid Research, Technical Documentary Report No. ASD-TDR-62-372, p. 323 (1962).

[39] T. G Fox and P. J. Flory, J. Am. Chem. Soc. Yo, 2384 (1948); J. Appl. Phys. 21, 581 (1950); J. Phys. and 
Colloid Chem. 55, 221 (1951); J. Polymer Sci. 14, 315 (1954); T. G. Fox and H. Nakayasu, Rheol. Bull. 29, $3(1960)$.

[40] T. G Fox and S. Loshaek, J. Appl. Phys. 26, 1080 (1955).

[41] J. F. Rudd, J. Polymer Sci. 44, 459 (1960).

[42] R. S. Porter and J. F. Johnson, J. Polymer Sci. 50, 379 (1961); Polymer 3, 11 (1962); Trans. Soc. Rheology \%, 241 (1963).

[43] N. C. Bletso, Ph.D. Thesis, University of Akron, Akron, Ohio (1962).

[44] J. W. Berge, P. R. Saunders and J. D. Ferry, J. Colloid Colloid Sci. 14, 135 (1959).

[45] K. Ueberreiter and H. J. Orthmann, Kolloid-Z. 126, 140 (1952).

[46] R. S. Porter and J. F. Johnson, J. Appl. Phys. 32, 2326 (1961).
[47] J. T. Gruver and G. Kraus, J. Polymer Sci. 2A, 797 (1964).

[48] S. Hayashi, J. Physical Soc. (Japan) 19, 101 (1964).

[49] Y. Chikahisa, J. Physical Soc. (Japan) 19, 92 (1964).

[50] M. Morton and L. J. Fetters, J. Polymer Sci. 2A, 3311 (1964).

[51] P. J. Flory, Principles of Polymer Chemistry (Cornell University Press, Ithaca, N. Y., 1953).

[52] A. R. Payne, Chapter in P. Mason and N. Wookey, Ed. Rheology of Elastomers (Pergamon Press, London, 1958).

[53] L. J. Zapas, S. L. Shufler and T. W. DeWitt, J. Polymer Sci. 18, 245 (1955).

[54] F. Bueche, J. Polymer Sci. 25, 305 (1957).

(Paper 69A1-325) 